University of Nebraska - Lincoln

DigitalCommons@University of Nebraska - Lincoln

Sociology Department, Faculty Publications

Sociology, Department of

$5-2009$

\title{
Depressive Symptoms, Gender, and Growth in Cigarette Smoking among Indigenous Adolescents
}

\author{
Les B. Whitbeck \\ University of Nebraska-Lincoln, Iwhitbeck2@unl.edu \\ ManSoo Yu \\ University of Missouri, Columbia, \\ Dennis E. McChargue \\ University of Nebraska-Lincoln, dmcchargue2@unl.edu \\ Devan M. Crawford \\ University of Nebraska-Lincoln, dcrawford3@unl.edu
}

Follow this and additional works at: https://digitalcommons.unl.edu/sociologyfacpub

Part of the Sociology Commons

Whitbeck, Les B.; Yu, ManSoo; McChargue, Dennis E.; and Crawford, Devan M., "Depressive Symptoms, Gender, and Growth in Cigarette Smoking among Indigenous Adolescents" (2009). Sociology Department, Faculty Publications. 70.

https://digitalcommons.unl.edu/sociologyfacpub/70

This Article is brought to you for free and open access by the Sociology, Department of at DigitalCommons@University of Nebraska - Lincoln. It has been accepted for inclusion in Sociology Department, Faculty Publications by an authorized administrator of DigitalCommons@University of Nebraska - Lincoln. 


\title{
Depressive Symptoms, Gender, and Growth in Cigarette Smoking among Indigenous Adolescents
}

\author{
Les B. Whitbeck, ${ }^{\mathrm{a}}$ ManSoo Yu, ${ }^{\mathrm{c}}$ Dennis E. McChargue, ${ }^{\mathrm{b}}$ and Devan M. Crawford ${ }^{\mathrm{a}}$ \\ a Department of Sociology, University of Nebraska-Lincoln, Lincoln, NE, USA \\ ${ }^{b}$ Department of Psychology, University of Nebraska-Lincoln, Lincoln, NE, USA \\ ' School of Social Work, Public Health Program, University of Missouri, Columbia, MO, USA \\ Corresponding author - L. B. Whitbeck, University of Nebraska-Lincoln, Department of Sociology, 739 Oldfather Hall, \\ Lincoln, NE 68588-0324, USA; tel 402 472-5562, fax 402 472-4983, email lwhitbeck2@unlnotes.unl.edu
}

\begin{abstract}
This study reports findings from two-level growth curve modeling of cigarette smoking and depressive symptoms based on the first three waves of data from a longitudinal study of Indigenous adolescents and their parents/caretakers in the northern Midwest and Canada. The 743 adolescents were aged 10-13 years at Wave 1 and 12-15 years at Wave 3. Over the three years of the study the overall retention rate was $93 \%$. By Wave $3,39 \%$ of the adolescent girls and $25 \%$ of the boys had smoked cigarettes in the past 12 months. The growth curve results indicated that smoking increased for both adolescent boys and girls across time. Depressive symptoms were associated with an increase in cigarette smoking for girls but not boys.
\end{abstract}

Keywords: cigarette smoking, indigenous adolescents, depressive symptoms

\section{Introduction}

Although prevalence rates vary greatly by culture and communities within cultures (Cantrell et al., 2005; Henderson et al., 2005; Spear et al., 2005), Indigenous (North American Indians, Alaska Natives and Canadian First Nations people) adults on average have higher rates of cigarette smoking than any other ethnic group (CDC, MMWR, 1999). The same is true for Indigenous adolescents aged 12-17 years. Their 30-day prevalence of cigarette smoking (23.1\%) is higher than their European American (14.9\%), African American (6.5\%), Latino, (9.3\%) or Asian (4.2\%) counterparts (CDC, MMWR, 2006). Such high rates of cigarette smoking are a major public health concern. Lung cancer is the leading cause of death among Indigenous people aged 55 years and older (CDC, 2003). Cigarette smoking also contributes to higher risk for cardiovascular disease among Indigenous adults compared to nonIndigenous adults (Harwell et al., 2001; Rhodes, 2005). Incidence rates for coronary heart disease among U.S. Indigenous adults are twice those of non-Indigenous adults reported in the Atherosclerosis Risk in Communities Study (Howard et al., 1999).

Risk for nicotine dependence occurs early and progresses rapidly. General population studies indicate that smoking rates climb most rapidly from middle school to high school (Eichner et al., 2005). In a diagnostic study of Indigenous adolescents, DSM-IV nicotine dependence increased from $1.7 \%$ at age $10-12$ years to 9.6\% at ages $13-15$ years (Whitbeck, Yu, Johnson, Hoyt, \& Walls, 2008). Given early onset and high lifetime prevalence rates of cigarette smoking among Indigenous people, we know surprisingly little about its etiology among Indigenous children and adolescents. This report presents findings from the first three waves of a longitudinal study of Indigenous adolescents in the northern Midwest. We employed two-level growth curve modeling to investigate the relationship between early onset cigarette smoking and depressive symptoms among early adolescents aged 10-12 years at Wave 1 and 13-15 years at Wave 3 .

\subsection{Depressive symptoms and cigarette smoking}

There is convincing evidence that cigarette smoking and depressive symptoms co-occur. Comorbidity rates for smoking and depression range from 31\%-60\% (Borrelli et al., 1996; Breslau et al., 1991; Glassman et al., 1990). Most of the studies linking cigarette smoking to depression, however, have been cross-sectional, begging the question of the direction of the relationship (Acierno et al., 2000; Anda et al., 1990; Escobedo et al., 1996; Glassman et al., 1990; Nezami et al., 2005; Weiss et al., 2005) and findings from prospective studies have been mixed regarding the direction of effects. For example, Munafo and colleagues reported that the level of depressed mood predicted progression to smoking initiation but depressed mood predicted progression from initiation to regular smoking only for female adolescents (Munafò et al., 2007). In a six-wave cohort study, Patton and associates found that depressive symptoms increased the likelihood of smoking only in the presence of peer smoking (Patton et al., 1998). Based on a 21year longitudinal study, Fergusson and colleagues found a robust association for depression and smoking even after control- 
ling for potential confounding variables. However, because risk factors for both so overlapped, the authors felt they could not confidently conclude causality. Still another longitudinal study based on the National Longitudinal Study of Adolescent Health (Add Health) concluded the relationship was bidirectional (Needham, 2007). Goodman and Capitman (2000), again using the Add Health waves 1 and 2, concluded that early depressive symptoms did not lead to cigarette smoking, rather that current cigarette use predicted depressive symptoms.

\subsection{Gender, depressive symptoms and cigarette smoking}

Several studies have reported that the effects of depressive symptoms on smoking or the transition to regular smoking were stronger for adolescent girls than for boys (Acierno et al., 2000; Munafò et al., 2007; Needham, 2007). Kubik and colleagues reported that female adolescents with elevated depressive symptoms were three times more likely to report cigarette smoking in the past 30 days than those with lower or no depressive symptoms (Kubik, Lytle, Birnbaum, Murray, \& Perry, 2003). Furthermore, there is evidence that adolescent females with elevated subsyndromal depressive symptoms who did not meet criteria for major depressive disorder started smoking earlier, were less motivated to quit smoking, and were more prone to experience frequent elevations in depressive symptoms (Borrelli et al., 1999; Borrelli et al., 1996).

\subsection{Depressive symptoms among Indigenous adolescents}

There have been several studies of depressive symptoms among Indigenous adults and adolescents that investigate the validity of symptom measures such as the CES-D (Beals et al., 1991; Somervell et al., 1993; Thrane et al., 2004) and address cultural variations in the expression of depressive symptoms (Beals et al., 2005; Manson, 1994; O’Nell, 1996). Symptoms studies indicate that the factor structure of the CES-D differs slightly from that for nonIndigenous adolescents but that the measure is highly reliable (Beals et al., 1991; Dick et al., 1994; Radloff, 1991). Beals and colleagues reported a mean CES-D score of 16.2 for a sample of Indigenous college students with $45 \%$ of the sample above the cutoff score of 16 and $13.3 \%$ above the more stringent cut-off of 28 , the 95th percentile in Radloff's work (Beals et al., 1991; Radloff, 1991). Manson and colleagues reported an average CES-D score of 19.4 among Indigenous boarding high school students. These are higher average scores than those reported in non-Indigenous samples. In the only recent diagnostic study of Indigenous adolescents Whitbeck and colleagues found that the rates of mood disorders were similar to those of adolescents in the general population (Whitbeck et al., 2008).

\subsection{Hypotheses}

This array of findings indicates that the relationship between cigarette smoking and depressive symptoms is very complex. Although the preponderance of evidence suggests that depressive symptoms, gender, and cigarette smoking are linked, we do not yet understand the specific mechanisms at work or the direction of the relationships. For example, it is possible that cigarette smoking emerges in response to depressive symptoms due to nicotine's presumed antidepressant effects (Kubik et al., 2003) or, conversely, smoking may begin as non-conventional behavior in adolescence as part of problem behavior syndrome (Donovan and Jessor, 1985; Jessor and Jessor, 1977) and depressive symptoms may emerge later in response to the consequences of maladaptive behaviors. Moreover, we have little information on how the relationship between depression and cigarette smoking may vary by culture. Rates of cigarette smoking are very high in some Indigenous cultures. It may well be that when smoking is so normative in some cultures that there is no link with depressive symptoms.

In this study we investigated potential relationships between depressive symptoms and the early onset of cigarette smoking among Indigenous adolescents. An advantage of this study is that we begin at an age level where both smoking behavior and depressive symptoms are apt to be low. Depressive symptoms tend to emerge with the onset of puberty, particularly among girls and increase through mid- and late adolescence. For example, adolescents aged 16-17 years were more than twice as likely to meet criteria for major depressive episode $(12.3 \%)$ than those aged $12-$ 13 years $(5.4 \%)$ (SAMHSA, 2005). Smoking behavior emerges concurrently with this age-related increase in depressive symptoms during the middle school and high school years (Eichner et al., 2005).

Following the findings of Borelli and others pertaining to European adolescents, we hypothesized that depressive symptoms would be positively associated with the onset of cigarette smoking among Indigenous adolescents (Borrelli et al., 1996, 1999). We also predicted gender differences in the emergence of depressive symptoms and cigarette use. There is convincing research showing that adolescent girls manifest higher levels of depressive symptoms than adolescent boys (see Angold \& Costello, 2001 for a review). Based on these findings and evidence regarding gender differences in the effects of depressive symptoms on smoking (Borrelli et al., 1996, 1999; Kubik et al., 2003), we hypothesized that depressive symptoms would have greater effects on early cigarette smoking among Indigenous adolescent girls than among boys.

\section{Method}

\subsection{Procedures}

These data were collected as part of a lagged sequential study currently underway on four reservations in the Northern Midwest and four Canadian reserves that involves yearly interviews with the adolescent and at least one primary caretaker. The data are from Waves 1 (ages 10-13 years), 2, and 3 of the study. The data were collected on two U.S. reservations and one Canadian reserve from February through October, 2002 and from a closely related study on two U.S. reservations and three remote Canadian reserves February through October 2003. There was a one year lag between study sites for all of the waves. A total of four U.S. reservations and four Canadian reserves participated in the study.

The reservations/reserves in this sample range from more affluent U.S. casino reservations to remote Canadian reserves making it representative of one the most populous indigenous cultures in the United States and Canada. Three of the Canadian Reserves are classified as "remote" in that they are considerable distances from even small towns and are accessed by non-paved roads. The reserves and reservations share a common cultural tradition and language with minor regional variations in dialects. The long range purpose of the longitudinal study is to identify culturally specific resilience and risk factors that affect children's well-being and to then use the information to guide the development of culturally-based interventions.

The project was designed in partnership with the participating reservations and reserves. Prior to the application funding, the research team was invited to work on these reservations, and tribal resolutions were obtained. As part of our agreement to work together, the researchers promised that participating reservations would be kept confidential in published reports. On each participating reservation, an advisory board was appointed by the tribal council. The advisory boards were responsible for advising regarding difficult personnel problems, questionnaire development, and assuring that published reports were respectful and protected the identity of the respondents and the culture. Upon advisory 
board consensus of the questionnaires, the study procedures and questionnaires were submitted for review by the university Institutional Review Board for approval.

All of the interviewers on the reservations/reserves were approved by the advisory board and were either tribal members or, in a very few cases (three or four out of approximately 45 interviewers), non-members who are spouses of tribal members. Each reservation/reserve had a local Indigenous full time interviewer supervisor who coordinated visits and provided quality control, including first edits. To ensure quality of data collection, all the interviewers underwent special training for conducting computer assisted personal interviews. The training took place onsite over a period of three days and included practice interviews and feedback sessions regarding interview quality. Prior to each wave of data collection each interviewer submitted interviews for feedback. By Wave 3 of the study we had a core group of highly experienced local supervisors and interviewers who were very comfortable with personal interviewing. All of the interviewers completed annual questionnaire trainings including required human subjects protection certification that emphasized the importance of confidentiality and taught procedures to maintain the confidentiality of data.

\subsection{Sample}

At Wave 1, each tribe provided a list of families of enrolled children aged 10-12 years who lived on or proximate to (within 50 miles) the reservation or reserve. We attempted to contact all families with a target child within the specified age range. Families were recruited with a personal visit by an Indigenous interviewer at which time the project was explained to them. They were then presented with a traditional gift and invited to participate. If they agreed to be interviewed, each family member received $\$ 40$ for their time when the interviews were completed. The recruitment procedure resulted in an overall response rate of $79.4 \%$. For as intrusive a design as this, we believe the response rate was very respectable. However, the most dysfunctional and substance abusing families were likely to refuse which may lend a conservative bias to our findings.

During the three years between Waves 1 and 3, the sample was reduced from 743 to 694 adolescents. The annual retention rates have been very high, ranging from $93 \%-100 \%$ with $93 \%$ overall retention from Wave 1 to Wave 3. Of those who left the study, 3.4\% of the attrition was due to refusal to participate. Other reasons for attrition included the death of the study adolescent (2 individuals) and loss of contact with the family ( 25 families). There were no statistically significant differences in depressive symptoms or cigarette smoking between those who left the study and those who remained in the study for all three waves.

\subsection{Measures}

\subsubsection{Cigarette smoking}

Adolescent cigarette smoking was measured at each time point using a five point scale. Youth were asked if they had ever smoked cigarettes. If youth reported ever smoking, they were asked if they had smoked in the past 12 months. If they reported they had smoked in the past year, youths were asked how often in the past 12 months they smoked. Responses to these questions were combined into a five-point scale assessing the intensity of adolescent cigarette smoking ("no smoking $=0$ ", "less than once a month $=1$," "once a month $=2$, , " every week $=3$," and "nearly every day $\left.=4^{\prime \prime}\right)$.

Depressive symptoms were assessed with the Center for Epidemiologic Studies - Depression Scale (CES-D, Radloff, 1977, 1991), a 20-item self-report scale used to evaluate past week levels of depressive symptoms. It has been used extensively with Indigenous adolescents (Beals et al., 1991; Manson et al., 1990; Thrane et al.,
2004). Response categories are a four-point scale: 0 days, 1-2 days, 3-4 days, 5-7 days. Responses to the 20 items were summed. The scoring of positive items was reversed. The possible range of scores is 0 to 60 , with the higher scores indicating more depressive symptomology. Cronbach's alpha coefficient was 0.85 at baseline and 0.87 at the two follow-up waves in this study.

\subsection{Data analysis}

Growth curve modeling was used to examine the effect of depressive symptoms on early cigarette smoking across the three waves of data, specifically to test the effects of progression of depressive symptoms on change in cigarette smoking and whether these effects differed by gender. The growth curve model was used to investigate Level 1 (within person) change in cigarette use over time and Level 2 (between person) effects of depressive symptoms and gender on the slope of cigarette use over time. All of the analyses were conducted using SAS PROC MIXED full maximum likelihood method. Goodness of fit indices applied to the entire model for both fixed and random effects (SAS Institute Inc., 2006; Singer, 1998). The procedure assumes that data are missing at random, handles between and within subject effects similarly, and allows covariates to vary within a subject (Wolfinger \& Chang, 1995). Unstructured covariance matrix on the REPEATED statement was employed to tell SAS to not impose any structure on the variance covariance matrix for the level-2 residuals (Singer \& Willett, 2003). We utilized common fit indices to evaluate the models, including the Akaike's Information Criterion (AIC) and the Bayesian Information Criteria (Akaike, 1974; Schwarz, 1978). Residual assumptions such as normality and equal variances were checked after the model was fit to the data.

\section{Results}

\subsection{Bivariate patterns of adolescent cigarette use and depressive symp-} toms by gender

Past month cigarette smoking increased across time from $12 \%$ of the adolescents smoking cigarettes at Wave 1 to $32 \%$ at Wave 3 (Fig. 1). At baseline, both males and females reported similar rates of cigarette use (11\% vs. $14 \%$, respectively) but by Wave 3 , a clear gender pattern emerged where the number of female smokers $(39 \%)$ increased more rapidly than the number of male smokers $(25 \%)$.

For the total sample, there was little change in mean depressive symptoms scores across time (12.6 at Wave 1, 12.7 at Wave 2,

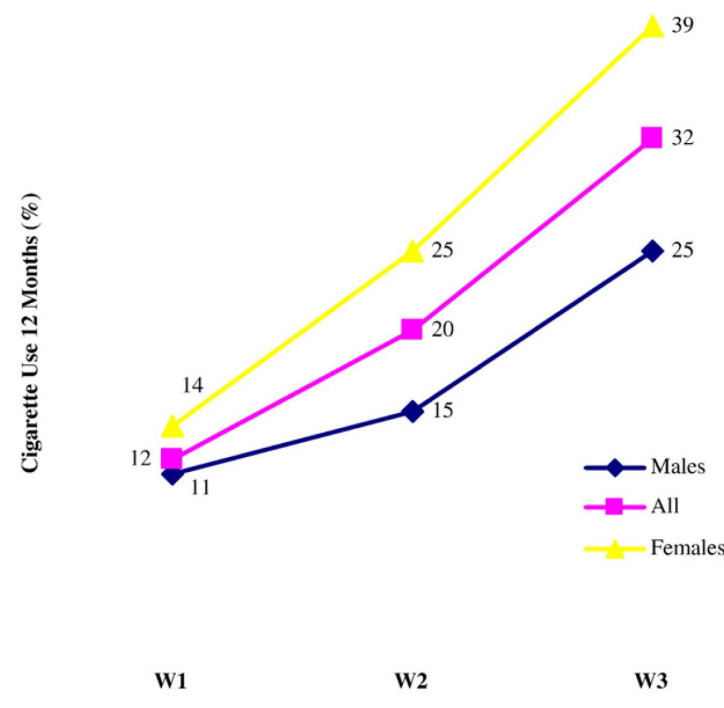

Figure 1. Patterns of change in cigarette use. 


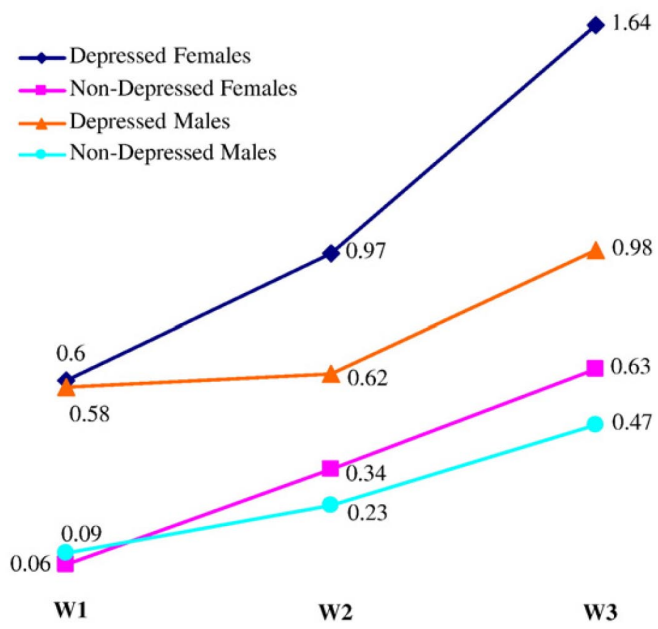

Figure 2. Depression and mean cigarette use by gender.

13.4 at Wave 3). Mean depression scores were not significantly different for male and female adolescents. Female depressive symptoms scores increased across time (13.1 at Wave 1, 13.6 at Wave 2, and 14.9 at Wave 3 ) while those for males remained relatively stable (12.0 at Wave 1, 11.8 at Wave 2, and 11.9 at Wave 3 ).

To investigate how depressive symptoms co-occurred with cigarette smoking, we dichotomized depressive symptoms into depressed (>16) and non-depressed (<16) categories (McDowell, $\&$ Newell, 1996) and plotted the mean scores of cigarette smoking by gender and depressive symptoms (Fig. 2). Adolescents who scored above the 16 point cutoff reported higher levels of cigarette

Table 1. Fixed and random effects from individual growth models predicting adolescent cigarette use

\begin{tabular}{|c|c|c|c|c|c|}
\hline \multirow[b]{2}{*}{ Model } & \multicolumn{5}{|c|}{ Parameter estimate (SE) } \\
\hline & 1 & 2 & 3 & 4 & 5 \\
\hline \multicolumn{6}{|l|}{ Fixed effects } \\
\hline Intercepts & $\begin{array}{l}.49^{* * *} \\
-(.03)\end{array}$ & $\begin{array}{l}-.08 \\
(.04)\end{array}$ & $\begin{array}{l}.04 \\
(.06)\end{array}$ & $\begin{array}{l}-.24^{* *} \\
(.08)\end{array}$ & $\begin{array}{l}-.15 \\
(.08)\end{array}$ \\
\hline Time & & $\begin{array}{l}.29^{* * *} \\
(.02)\end{array}$ & $\begin{array}{l}.18^{* * *} \\
(.04)\end{array}$ & $\begin{array}{l}.16^{* * *} \\
(.04)\end{array}$ & $\begin{array}{l}.09 \\
(.05)\end{array}$ \\
\hline Female & & & $\begin{array}{l}-.24^{* *} \\
(.08)\end{array}$ & & $\begin{array}{l}-.21 \\
(.08)\end{array}$ \\
\hline Time $\times$ Female & & & $\begin{array}{l}.24^{* * *} \\
(.05)\end{array}$ & & $\begin{array}{l}.19^{* * *} \\
(.05)\end{array}$ \\
\hline Depressive symptoms & & & & $\begin{array}{l}.01^{* *} \\
(.01)\end{array}$ & $\begin{array}{l}.02^{* *} \\
(.01)\end{array}$ \\
\hline Time $\times$ Depressive symptoms & & & & $\begin{array}{l}.01^{\text {*** }}(.00) \\
\text { (a) }\end{array}$ & $\begin{array}{l}.01^{* *} \\
(.00)\end{array}$ \\
\hline \multicolumn{6}{|l|}{ Random effects } \\
\hline Level 1: Within-person (Residual) & $\begin{array}{l}.78^{* * *} \\
(.03)\end{array}$ & $\begin{array}{l}.47^{* * *} \\
(.02)\end{array}$ & $\begin{array}{l}.47^{* * *} \\
(.02)\end{array}$ & $\begin{array}{l}.46^{* * *} \\
(.02)\end{array}$ & 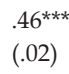 \\
\hline Level 2: Initial status & $\begin{array}{l}.50^{* * *} \\
(.04)\end{array}$ & $\begin{array}{l}.18^{*} \\
(.09)\end{array}$ & $\begin{array}{l}.16^{*} \\
(.09)\end{array}$ & $\begin{array}{l}.13 \\
(.09)\end{array}$ & $\begin{array}{l}.12 \\
(.09)\end{array}$ \\
\hline Level 2: Rate of change (Slope) & & $\begin{array}{l}.22^{* * *} \\
(.03)\end{array}$ & $\begin{array}{l}.20^{* * *} \\
(.03)\end{array}$ & $\begin{array}{l}.20^{* * *} \\
(.03)\end{array}$ & 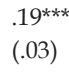 \\
\hline Level 2: Covariance & & $\begin{array}{l}-.10^{*} \\
(.04)\end{array}$ & $\begin{array}{l}-.09^{*} \\
(.04)\end{array}$ & $\begin{array}{l}-.10^{*} \\
(.04)\end{array}$ & $\begin{array}{l}-.09^{\prime} \\
(.04)\end{array}$ \\
\hline \multicolumn{6}{|l|}{ Goodness of fit } \\
\hline - 2 log-likelihood (Deviance) & 6293 & 5797 & 5769 & 5649 & 5632 \\
\hline Akaike Information Criterion (AIC) & 6299 & 5809 & 5785 & 5665 & 5652 \\
\hline Bayesian Information Criterion (BIC) & 6313 & 5837 & 5822 & 5702 & 5698 \\
\hline
\end{tabular}

use than those who were not depressed regardless of gender. Depressed females reported significantly higher rates of cigarette use compared to depressed males at Wave $3(p=.003)$. There was no statistically significant difference in smoking between non-depressed males and females.

3.2. Gender difference in the effect of growth in depressive symptoms on cigarette use

We used two-stage growth models for a multivariate analysis of the descriptive findings, Table 1 presents the results from unconditional and conditional individual growth models. The unconditioned means model without any predictors (Model 1) serves for model comparison where the average score on cigarette smoking is less than once a month $\left(\gamma_{00}=0.49, p<.001\right)$.

$$
Y_{i j}=r_{00}+\mu_{0 j}+r_{i j}
$$

Model 2 is an unconditional individual growth model including only the main effect of time. The model indicated that the average of adolescents' cigarette smoking began with a score of 0.08 $\left(r_{10}=0.08\right)$, on average (essentially no cigarette use) and the estimate of the average slope of cigarette use gained 0.29 per Wave $\left(\gamma_{10}=0.29, p<.001\right)$.). The average increase in cigarette smoking was statistically significant for both males and females.

$$
Y_{i j}=\gamma_{00}+\gamma_{10}(\text { Time })_{i j}+\mu_{0 j}+\mu_{1 j}(\text { Time })_{i j}+r_{i j}
$$

Model 3 added the main effect of gender and the gender and time interaction term. After controlling for the main effects of both time and gender, there was a positive interaction between gender and time in predicting growth in adolescent cigarette use $\left(\gamma_{11}=.24, p<.001\right)$. The findings indicated that the slope of change in cigarette smoking among female adolescents was steeper than

Table 2. Fixed and random effects from individual growth models

\begin{tabular}{|c|c|c|c|c|c|c|}
\hline \multirow[b]{3}{*}{ Model } & \multicolumn{6}{|c|}{ Parameter estimate (SE) } \\
\hline & \multicolumn{3}{|c|}{ Females } & \multicolumn{3}{|c|}{ Males } \\
\hline & $1 \mathrm{a}$ & $2 \mathrm{a}$ & $3 a$ & $1 b$ & $2 b$ & $3 b$ \\
\hline \multicolumn{7}{|l|}{ Fixed effects } \\
\hline Intercepts & $\begin{array}{l}.60^{* * *} \\
(.05)\end{array}$ & $\begin{array}{l}-.21^{* * *} \\
(.06)\end{array}$ & $\begin{array}{l}-.36^{* * *} \\
(.11)\end{array}$ & $\begin{array}{l}.39^{* * * *} \\
(.04)\end{array}$ & $\begin{array}{l}.04 \\
(.06)\end{array}$ & $\begin{array}{l}-.20 \\
(.11)\end{array}$ \\
\hline Time & & $\begin{array}{l}.42^{* * *} \\
(.04)\end{array}$ & $\begin{array}{l}.25^{* * *} \\
(.06)\end{array}$ & & $\begin{array}{l}.18^{* * *} \\
(.02)\end{array}$ & $\begin{array}{l}.14^{*} \\
(.06)\end{array}$ \\
\hline Female & & & $\begin{array}{l}.02 * \\
(.01)\end{array}$ & & & $\begin{array}{l}.02 * \\
(.01)\end{array}$ \\
\hline Time $\times$ Female & & & $\begin{array}{l}.01^{*} \\
(.00)\end{array}$ & & & $\begin{array}{l}.00 \\
(.00)\end{array}$ \\
\hline \multicolumn{7}{|l|}{ Random effects } \\
\hline \multicolumn{2}{|c|}{$\begin{array}{l}\text { Level 1: Within-person (Residual) } \\
.41^{* * *}\end{array}$} & $.96^{* * *}$ & $.51^{* * *}$ & $.50^{* * *}$ & $.60^{* * *}$ & $.43^{* * *}$ \\
\hline & $(.05)$ & $(.04)$ & $(.03)$ & $(.03)$ & $(.03)$ & $(.03)$ \\
\hline Level 2: Initial status & $\begin{array}{l}.55^{* * *} \\
(.07)\end{array}$ & $\begin{array}{l}.06 \\
(.13)\end{array}$ & $\begin{array}{l}.00 \\
(.00)\end{array}$ & $\begin{array}{l}.43^{* * *} \\
(.05)\end{array}$ & $\begin{array}{l}.23^{*} \\
(.12)\end{array}$ & $\begin{array}{l}.23^{*} \\
(.12)\end{array}$ \\
\hline Level 2: Rate of change (Slope) & & $\begin{array}{l}.28^{* * *} \\
(.04)\end{array}$ & $\begin{array}{l}.25^{* * * *} \\
(.03)\end{array}$ & & $\begin{array}{l}.13^{* * *} \\
(.03)\end{array}$ & $\begin{array}{l}.14^{* * *} \\
(.03)\end{array}$ \\
\hline Level 2: Covariance & & $\begin{array}{l}-.09 \\
(.07)\end{array}$ & $\begin{array}{l}-.09^{* * *} \\
(.03)\end{array}$ & & $\begin{array}{l}-.07 \\
(.05)\end{array}$ & $\begin{array}{l}-.08 \\
(.05)\end{array}$ \\
\hline Goodness of fit & & & & & & \\
\hline - 2 log-likelihood (Deviance) & 3331 & 2974 & 2885 & 2897 & 2766 & 2718 \\
\hline $\begin{array}{l}\text { Akaike Information } 3337 \\
\text { Criterion (AIC) }\end{array}$ & 2986 & 2899 & 2903 & 2778 & 2734 & \\
\hline $\begin{array}{l}\text { Bayesian Information } 3349 \\
\text { Criterion (BIC) }\end{array}$ & 3010 & 2926 & 2915 & 2801 & 2765 & \\
\hline
\end{tabular}
predicting adolescent cigarette use by gender 
the slope among male youths, consistent with descriptive patterns of cigarette use over time in Fig. 1.

$$
\begin{aligned}
Y_{i j}= & \gamma_{00}+\gamma_{10}(\text { Time })_{i j}+\gamma_{01}(\text { Female })_{j} \\
& +\gamma_{11}(\text { Female })_{j} \times(\text { Time })_{i j}+\mu_{0 j}+\mu_{1 j}(\text { Time })_{i j}+r_{i j}
\end{aligned}
$$

Model 4 included an interaction term for time and depressive symptoms, as well as the main effects for depressive symptoms. As hypothesized, the change in depressive symptoms increased the likelihood of cigarette use across time $\left(\gamma_{12}=.01, p=.001\right)$. The main effect of depressive symptoms on growth remained statistically significant $\left(\gamma_{02}=.01, p=.005\right)$.

$$
\begin{aligned}
Y_{i j}= & \gamma_{00}+\gamma_{10}(\text { Time })_{i j}+\gamma_{02}(\text { CES-D })_{j} \\
& +\gamma_{12}(\text { CES-D })_{j} \times(\text { Time })_{i j}+\mu_{0 j}+\mu_{1 j}(\text { Time })_{i j}+r_{i j}
\end{aligned}
$$

Model 5 includes both gender and depressive symptoms and interactions with time to investigate their simultaneous effects on the slope of adolescent cigarette use. All predictors remained significant, with the exception of the main effect of time $(p=.07)$ on growth. Being female $\left(\gamma_{01}=-.21, p=.01\right)$ and depressive symptoms $\left(\gamma_{02}=.02, p=.002\right)$ independently predicted the rate of cigarette use. Furthermore, gender and depressive symptoms significantly interacted with time, increasing the rate of cigarette use.

$$
\begin{aligned}
Y_{i j} & =\gamma_{00}+r_{10}(\text { Time })_{i j}+\gamma_{01}(\text { Female })_{j}+\gamma_{11}(\text { Female })_{j} \times(\text { Time })_{i j} \\
& +\gamma_{02}(\text { CES-D })_{j}+r_{12}(\text { CES-D })_{j} \times(\text { Time })_{i j}+\mu_{0 j}+\mu_{1 j}(\text { Time })_{i j}+r_{i j}
\end{aligned}
$$

Based on the significant effect of gender on growth in cigarette use across time, we ran separate growth models by gender. As shown in Table 2, the main effect of depressive symptoms and time on growth in cigarette use was significant for male and female adolescents. However, the interaction term for time and depressive symptoms was statistically significant only for female adolescents $(p=.011)$.

\section{Discussion and conclusions}

These results are congruent with other findings showing that cigarette smoking increases dramatically among adolescents from early to mid-adolescence (Eichner et al., 2005). By Wave 3, 39\% of the adolescent girls and $25 \%$ of the boys had smoked cigarettes in the past 12 months. Our results also support Borelli and colleagues findings in that depressive symptoms were associated with increased cigarette use among adolescent girls, but not boys (1999).

The rates of adolescent smoking in our study portend a heavy health care burden later in life. Given the likelihood that depressive symptoms may recur later in adolescence and in adulthood (Dunn and Goodyer, 2006; Mueller et al., 1999) and emerging evidence in human (Glassman et al., 1990; Salin-Pascual et al., 1996) and animal studies (Mineur et al., 2007; Suemaru et al., 2006) that nicotine may have antidepressant effects, young smokers who are depressed are likely to be life-long smokers. The association between depressive symptoms and cigarette smoking among individuals this young is particularly insidious in that there is evidence that smokers with depressive symptoms smoke more and have more difficulty quitting smoking than smokers without depressive symptoms (Borrelli et al., 1999).

The most important limitation of this study is that it is based on a single Indigenous culture and may not be generalizable across the diversity of North American Indigenous nations. Smoking behaviors are highly likely to vary between and within Indigenous cultures. Furthermore, even though our data are from several sites, they reflect the attitudes and behaviors of people who live on or near rural and remote reservations and reserves. The findings may not represent urban Indigenous people even from the same cultural background. Finally, although the CES-D has been widely used with Indigenous adolescents and adults, it is not clear that depressive symptoms are expressed similarly by Indigenous and non-Indigenous people (Manson et al., 1990).

These findings have implications for both prevention and treatment of Indigenous adolescent nicotine use. First, as with all adolescents cigarette use increases very quickly at relatively young ages. Prevention programs should take this into account and target children at ages before they begin experimenting with smoking. Second, smoking cessation programs should be available for adolescent smokers and they should take into account the effects of depressive symptoms on smoking behaviors. Screening for depressive symptoms should be included in cessation programs and depressed adolescents referred for simultaneous treatment. Finally, the gender effect was strong and persistent across time among Indigenous adolescents. Female-only prevention and cessation programs may be more effective in reducing cigarette use among Indigenous adolescent girls. More research is needed that addresses specific mechanisms that account for early smoking among Indigenous adolescent girls and boys.

\section{Acknowledgment}

This research was funded by the National Institute on Drug Abuse (DA13580) and the National Institute of Mental Health (MH67281), Les B. Whitbeck, Principal Investigator.

\section{References}

Acierno et al., $2000 \bullet$ R. Acierno, D. Kilpatrick, H. Resnick, B. Saunders, De Arellano, and C. Best, Assault, PTSD, family substance use, and depression as risk factors for cigarette use in youth: Findings from the National Survey of Adolescents, Journal of Traumatic Stress 13 (2000), pp. 381-396.

Akaike, $1974 \bullet$ H. Akaike, A new look at the statistical model identification, IEEE Transactions on Automatic Control 19 (6) (1974), pp. $716-723$.

Anda et al., 1990 - R. Anda, D. Williamson, L. Escobedo, E. Mast, G. Giovino, and P. Remington, Depression and the dynamics of smoking: A national perspective, Journal of the American Medical Association 264 (1990), pp. 1541-1584.

Angold and Costello, $2001 \bullet$ A. Angold and E. Costello, The epidemiology of depression in children and adolescents. In: I.M. Goodyer, Editor, The depressed child and adolescent (2nd Ed.), Cambridge University Press, Cambridge, UK (2001), pp. 143-178.

Beals et al., $1991 \bullet$ J. Beals, S. Manson, E. Keane, and R. Dick, Factorial structure of the center for epidemiology studies-depression scale among American Indian college students, Psychological Assessment 3 (1991), pp. 623-627.

Beals et al., $2005 \bullet$ J. Beals, S. Manson, N. Whitesell, C. Mitchell, D. Novins, and S. Simpson et al., Prevalence of major depressive episode in two American Indian reservation populations: Unexpected findings with a structured interview, American Journal of Psychiatry 162 (2005), pp. 1713-1722.

Borrelli et al., 1999 • B. Borrelli, B. H. Marcus, M. M. Clark, B. C. Bock, T.K. King, and M. Roberts, History of major depression and subsyndromal depression in women smokers, Addictive Behaviors 24 (6) (1999), pp. 781-794.

Borrelli et al., 1996 • B. Borrelli, R. Niaura, N. Keuthan, M. Goldstein, J. DePue, and C. Murphy et al., Development of major depressive disorder during smoking cessation treatment, Journal of Clinical Psychiatry 57 (11) (1996), pp. 534-538.

Breslau et al., 1991 • N. Breslau, M. M. Kilbey, and P. Andreski, Nicotine dependence, major depression, and anxiety in young adults, Archives of General Psychiatry 48 (12) (1991), pp. 1069-1074.

Cantrell et al., $2005 \bullet$ B. Cantrell, F. Hodge, R. Struthers, and L. Decora, The high incidence of cigarette smoking among American Indians of the northern plains, Journal of Cancer Education 20 (2005), pp. 97-100.

CDC, 1999 - CDC, Cigarette smoking among adults-United States, 1997, Morbidity and Mortality Weekly (MMWR) 48 (1999), pp. 993-996. 
CDC, 2003 • CDC. (2003). National vital statistics. Deaths leading causes for 2003.

CDC, $2006 \bullet$ CDC, Racial/Ethnic Differences Among Youths in Cigarette Smoking and Susceptibility to Start Smoking - United States, 20022004 (No. MMWR 55(47)) (2006).

Dick et al., $1994 \bullet$ R. Dick, J. Beals, E. Keane, and S. Manson, Factorial structure of the CES-D among American Indian adolescents, Journal of Early Adolescence 17 (1994), pp. 73-79.

Donovan and Jessor, $1985 \bullet$ J. Donovan and R. Jessor, Structure of problem behavior in adolescence and young adulthood, Journal of Consulting and Clinical Psychology 58 (1985), pp. 890-904.

Dunn and Goodyer, $2006 \bullet$ V. Dunn and I. Goodyer, Longitudinal investigation into childhood and adolescent-onset depression: Psychiatric outcome in early adulthood, British Journal of Psychiatry 188 (2006), pp. 216-222.

Eichner et al., $2005 \bullet$ J. E. Eichner, K. Cravatt, L. A. Beebe, K. S. Blevins, M. L. Stoddart, and Z. Bursac et al., Tobacco use among American Indians in Oklahoma: An epidemiologic view, Public Health Reports 120 (2) (2005), pp. 192-199.

Escobedo et al., 1996 - L. Escobedo, D. Kirch, and R. Anda, Depression and smoking initiation among U.S. Latinos, Addiction 91 (1996), pp. 113-119.

Glassman et al., 1990 • A. H. Glassman, J. E. Helzer, L. S. Covey, L. B. Cottler, F. Stetner, and J. E. Tipp et al., Smoking, smoking cessation, and major depression, The Journal of the American Medical Association (JAMA) 264 (12) (1990).

Goodman and Capitman, 2000 • E. Goodman and J. Capitman, Depressive symptoms and cigarette smoking among teens, Pediatrics 106 (2000), pp. 748-755.

Harwell et al., $2001 \bullet$ T. S. Harwell, D. Gohdes, K. Moore, J. M. McDowall, J. G. Smilie, and S. D. Helgerson, Cardiovascular disease and risk factors in Montana American Indians and non-Indians, American Journal of Preventive Medicine 20 (3) (2001), pp. 196-201.

Henderson et al., $2005 \bullet$ P. Henderson, C. Jacobsen, and J. Beals, Correlates of cigarette smoking among selected Southwest and northern plains tribal groups: The AI-SUPERPFP study, American Journal of Public Health 95 (2005), pp. 867-872.

Howard et al., 1999 - B. Howard, E. Lee, L. Cowan, R. Devereux, J. Galloway, and O. Go et al., Rising tide of cardiovascular disease in American Indians, Circulation 99 (1999), pp. 2389-2395.

Jessor and Jessor, $1977 \bullet$ R. Jessor and S. L. Jessor, Problem behavior and psychological development: A longitudinal study of youth, Academic Press, New York (1977).

Kubik et al., $2003 \bullet$ M. Y. Kubik, L. A. Lytle, A. S. Birnbaum, D. M. Murray, and C. L. Perry, Prevalence and correlates of depressive symptoms in young adolescents, American Journal of Health Behavior 27 (5) (2003), pp. 546-553.

Manson, $1994 \bullet \mathrm{S}$. Manson, Culture and depression: Discovering variations in the experience of illness. In: W. Longer and R. Malpass, Editors, Psychology and culture, Allyn and Bacon, Needham, MA (1994), pp. 285-290.

Manson et al., $1990 \bullet$ S. Manson, L. Ackerson, R. Dick, A. Baron, and C. Fleming, Depressive symptoms among American Indian adolescents: Psychometric characteristics of the center for epidemiologic studies depression scale (CESD), Psychological Assessment 2 (1990), pp. 231-237.

McDowell and Newell, $1996 \bullet$ I. McDowell and C. Newell, Measuring Health: A Guide to Rating Scales and Questionnaires ((2nd ed.)), Oxford University Press, New York (1996).

Mineur et al., $2007 \bullet$ Y. Mineur, O. Somenzi, and M. Picciotto, Cytisine, a partial agonist of high affinity nicotinic acetylcholine receptors, has antidepressant-like properties in male C57BL/6J mice, Neuropharmacology 52 (2007), pp. 1256-1262.

Mueller et al., $1999 \bullet$ T. Mueller, A. Leon, M. Keller, D. Solomon, J. Endicott, and W. Coyell et al., Recurrence after recovery from major depressive disorder during 15 years of observational followup, American Journal of Psychiatry 156 (1999), pp. 1000-1006.

Munafò et al., $2007 \bullet$ M. R. Munafò, B. Hitsman, R. Rende, C. Metcalfe, and R. Niaura, Effects of progression to cigarette smoking on depressed mood in adolescents: Evidence from the National Longitudinal Study of Adolescent Health, Addiction 103 (1) (2007), pp. 162-171.
Needham, 2007 • B. Needham, Gender differences in trajectories of depressive symptomatology and substance use during the transition from adolescence to young adulthood, Social Science $\mathcal{E}$ Medicine 65 (2007), pp. 1166-1179.

Nezami et al., 2005 • E. Nezami, J. Unger, S. Tan, C. Maaffey, A. RittOlson, and S. Sussman et al., The influence of depressive symptoms on experimental smoking and intention to smoke in a diverse youth sample, Nicotine E Tobacco Research 7 (2005), pp. 243-248.

O'Nell, $1996 \bullet$ T. O'Nell, Disciplined hearts: History, identity, and depression in an American Indian community, University of California Press, Berkeley, CA (1996).

Patton et al., 1998 • G. C. Patton, J. B. Carlin, C. Coffey, R. Wolfe, M. Hibbert, and G. Bowes, Depression, anxiety, and smoking initiation: a prospective study over 3 years, American Journal of Public Health 88 (10) (1998), pp. 1518-1522.

Radloff, $1991 \bullet$ L. Radloff, The use of the center for epidemiologic studies depression scale in adolescents and young adults, Journal of Youth and Adolescence 20 (1991), p. 1991.

Radloff, $1977 \bullet$ L. S. Radloff, The CES-D scale: a self-report depression scale for research in the general population, Applied Psychological Measurement 1 (3) (1977), pp. 385-401.

Rhodes, $2005 \bullet$ D. Rhodes, Racial misclassification and disparities in cardiovascular disease among American Indians and Alaska Natives, Circulation 111 (2005), pp. 1250-1256.

Salin-Pascual et al., 1996 • R. Salin-Pascual, M. Rosas, A. JimenezGenchi, B. Rivera-Meza, and Delgado-Parra, Antidepressant effect of transdermal nicotine patches in nonsmoking patients with major depression, Journal of Clinical Psychiatry 57 (1996), pp. 387-389.

SAMHSA, $2005 \bullet$ SAMHSA, Depression among Adolescents (No. DHHS Publication No. SMA 05-4062, NSDUH Series H-28), The Office of Applied Studies, Substance Abuse and Mental Health Services Administration, Rockville, MD (2005).

SAS Institute Inc., 2006 • SAS Institute Inc., Base SAS 9.1.3 Procedures Guide, Second Edition, Volumes 1,2,3, and 4, SAS Institute Inc., Cary, NC (2006).

Schwarz, 1978 • G. Schwarz, Estimating the dimension of a model, The Annals of Statistics 6 (2) (1978), pp. 461-464.

Singer, $1998 \bullet$ J. D. Singer, Using SAS PROC MIXED to fit multilevel models, hierarchical models, and individual growth models, Journal of Educational and Behavioral Statistics 23 (4) (1998), pp. 323-355.

Singer and Willett, $2003 \bullet$ J. D. Singer and J. B. Willett, Applied Longitudinal Data Analysis: Modeling Change and Event Occurrence, Oxford University Press, New York (2003).

Somervell et al., 1993 • P. D. Somervell, J. Beals, J. D. Kinzie, J. Boehnlein, P. Leung, and S. M. Manson, Use of the CES-D in an American Indian village, Culture, Medicine and Psychiatry 16 (4) (1993), pp. 503-517.

Spear et al., $2005 \bullet$ S. Spear, D. Longshore, D. McCaffrey, and P. Ellickson, Prevalence of substance use among White and American Indian young adolescents in a Northern Plains State, Journal of Psychoactive Drugs 37 (1) (2005), pp. 1-6.

Suemaru et al., $2006 \bullet$ K. Suemaru, K. Yasuda, D. Cui, B. Li, K. Umeda, and M. Amano et al., Antidepressant-like action of nicotine in forced swimming test and brain serotonin in mice, Physiological Behavior 88 (2006), pp. 545-549.

Thrane et al., $2004 \bullet$ L. E. Thrane, L. B. Whitbeck, D. R. Hoyt, and M. C. Shelley, Comparing three measures of depressive symptoms among American Indian adolescents, American Indian and Alaska Native Mental Health Research 11 (3) (2004), pp. 20-42.

Weiss et al., $2005 \bullet$ J. Weiss, M. Mouttapa, C. Chou, E. Nexami, C. Johnson, and P. Palmer et al., Hostility, depressive symptoms, and smoking in early adolescence, Journal of Adolescence 28 (2005), pp. 49-62.

Whitbeck et al., $2008 \bullet$ L. Whitbeck, M. Yu, K. Johnson, D. Hoyt, and M. Walls, Diagnostic prevalence rates from early to mid-adolescence among Indigenous adolescents: First results from a longitudinal study, Journal of the American Academy of Child and Adolescent Psychiatry 47 (2008), pp. 95-104.

Wolfinger and Chang, $1995 \bullet \mathrm{R}$. Wolfinger and M. Chang, Comparing the SAS GLM and MIXED Procedures for Repeated Measures, SAS Institute Inc., Cary, NC (1995). 